\title{
Sensitive Detection of Glycyrrhizin and Evaluation of the Affinity Constants by a Surface Plasmon Resonance-based Immunosensor
}

\author{
Takatoshi SaKaI,* Katsura Shinahara,* Akira Torimaru,* Hiroyuki TanaKa,** \\ Yukihiro Shoyama,** and Kiyoshi Matsumoto*i \\ *Department of Bioscience and Biotechnology, Faculty of Agriculture, Kyushu University, \\ Fukuoka 812-8581, Japan \\ **Department of Chemo-Pharmaceutical Sciences, Faculty of Pharmaceutical Sciences, Kyushu University, \\ Fukuoka 812-8582, Japan
}

\begin{abstract}
A sensitive and selective determination of glycyrrhizin (GC) based on surface plasmon resonance (SPR) was performed by using an anti-GC monoclonal antibody (GC-MAb) and GC-bovine serum albumin (GC-BSA) conjugate (antigen). GC-BSA was immobilized on an Au thin film of the SPR sensor chip by physical adsorption, and GC determinations were performed by an indirect competitive method. The addition of GC into the GC-MAb solution $(5 \mu \mathrm{g} / \mathrm{ml})$ was found to decrease the incident-angle shift sharply because of an inhibition effect of GC. The RSDs $(n=3)$ of each point were less than 4\%. The lowest detection limit for GC by SPR was almost the same as that by ELISA, $60-75 \mathrm{ng} / \mathrm{ml}$. An evaluation of the affinity constant between GC-MAb and GC using the data from ELISA and those from SPR measurements was performed. The values of the association constant $\left(K_{\mathrm{A}}\right)$ from three different analyses of ELISA data and from SPR measurements are discussed in detail. As a whole, the affinity constant $\left(K_{\mathrm{A}}\right)$ between GC-MAb and GC was on the order of $10^{7} \mathrm{M}^{-1}$.
\end{abstract}

(Received September 8, 2003; Accepted December 8, 2003)

\section{Introduction}

Licorice (Glycyrrhiza spp.) root is one of the world's most common herbal medicines, used in European, Mideastern, Asian, and Chinese traditions. Glycyrrhizin (GC) is an extract from licorice root, and amounts to about $15 \%$ of the whole fresh root extract. The pharmaceutical properties of GC are, so far, reported as having protein kinase inhibitory activity, ${ }^{1}$ anti-ulcer ${ }^{2}$ and anti-viral ${ }^{3}$ activity, immunomodulatory activity against $\mathrm{HIV},{ }^{4}$ and therapeutic effects on liver disease. ${ }^{5}$ The rapid and selective quantitation of low-molecular-weight bioactive compounds is very important for investigating the distribution of the compounds in plants or animals and for elucidating the metabolism of such compounds. Measurements of GC using HPLC $^{6}$ and capillary electrophoresis ${ }^{7}$ have been reported. These methods, however, require a pretreatment in order to measure GC in plant extracts or serum samples.

Biochemical techniques using monoclonal antibodies (MAbs) are powerful tools for the detection of drugs and low-molecularweight bioactive compounds. Recently, Shan et al. developed a sensitive method for determining GC by using an enzyme linked immunosorbent assay (ELISA). ${ }^{8}$ Though it is sensitive and selective for measuring GC, it is still time consuming (in general, 3 - $4 \mathrm{~h}$ per assay).

An immunosensor based on surface plasmon resonance (SPR) has been receiving increasing attention in recent years, due to its potential as a label-free, real-time, rapid, high-selectivity

$\dagger$ To whom correspondence should be addressed.

E-mail: kmatsu@agr.kyushu-u.ac.jp immunoassay technique..$^{910}$ These methods are able to perform an assay in $5-30 \mathrm{~min}$.

In the present study, we aimed to develop a simple and rapid method for quantifying GC by SPR. In addition, we evaluated the affinity constants $\left(K_{\mathrm{A}}\right)$ between antigens and antibodies (GC and $\mathrm{GC}-\mathrm{MAb}$ ) by assuming a Langmuir adsorption model for the immunoreaction.

\section{Experimental}

\section{Chemicals and apparatus}

GC and Tween 20 were purchased from Wako Pure Chemicals Ind., Ltd. (Osaka, Japan). Bovine serum albumin (BSA), sodium periodate $\left(\mathrm{NaIO}_{4}\right), p$-nitrophenyl phosphate disodium salt ( $p$-NPP), and gelatin were from Nacalai Tesque, Inc. (Kyoto, Japan). Human immunoglobulin $\mathrm{G}(h \mathrm{IgG}$, reagent grade), anti- $h \mathrm{IgG}$ antibody (affinity purified) and alkaline phosphatase labelled anti-mouse IgG were provided by Sigma (St. Louis, MO, USA). All other chemicals were of analytical reagent grade. All buffer solutions were prepared using water purified with a Milli-Q (Millipore, Bedford, UK) system. AntiGC MAb 5A8 (GC-MAb, 5A8) was supplied by Tanaka and Shoyama. ${ }^{8}$

SPR measurements were performed using a Spreeta $^{\mathrm{TM}}$ evaluation module kit (Texas Instruments, Inc., Texas, USA) attached to a sensor chip, a flow-through cell $(2 \times 18 \times 0.2 \mathrm{~mm})$ and a microtube pump (EYELA, SMP-23S, Tokyo, Japan). ELISA measurements were performed using 96-well immunoplates (NUNC, No. 446612, Roskilde, Denmark) and a microplate reader (Spectra 1, Wako, Osaka, Japan). 


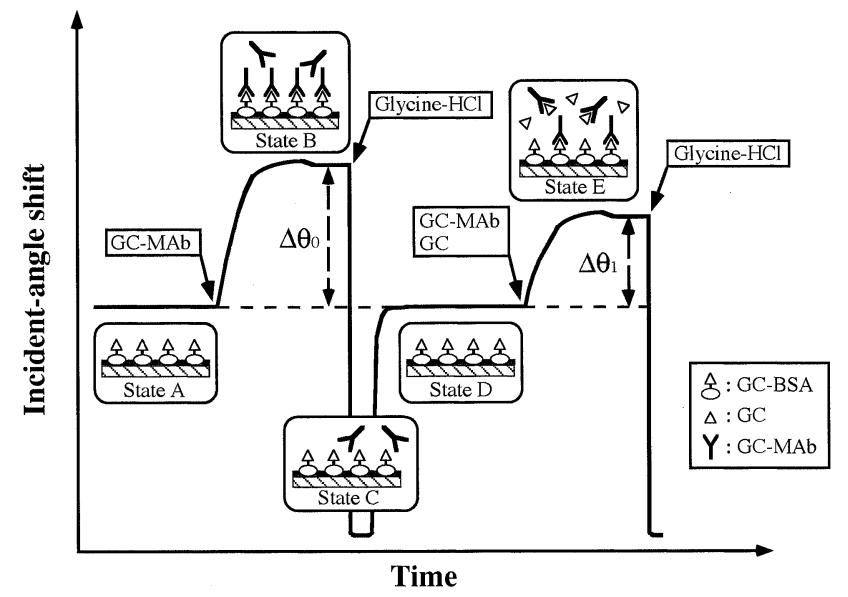

Fig. 1 Response transients of the GC-BSA immobilized sensor to the GC-MAb without antigen $\left(\theta_{0}\right)$ and with antigen $\left(\theta_{1}\right)$.

\section{Synthesis of GC-BSA conjugate}

GC-BSA conjugate was synthesized by a method reported by Shan et al. ${ }^{8}$ Briefly, a methanol solution $(0.27 \mathrm{ml})$ of GC (5.2 $\mathrm{mg})$ was added dropwise to a solution $(0.4 \mathrm{ml})$ containing $\mathrm{NaIO}_{4}(5 \mathrm{mg})$ and stirred at room temperature for $1 \mathrm{~h}$. Carbonate buffer $(50 \mathrm{mM}, \mathrm{pH} 9.6,1.4 \mathrm{ml})$ containing BSA (5 $\mathrm{mg}$ ) was added to the above-mentioned reaction mixture. The whole reaction mixture was adjusted to $\mathrm{pH} 9.0$ with a $1 \mathrm{M}$ $\mathrm{Na}_{2} \mathrm{CO}_{3}$ solution and stirred at room temperature for $6 \mathrm{~h}$. The reaction mixture was dialyzed against five changes of $\mathrm{H}_{2} \mathrm{O}$ at $4^{\circ} \mathrm{C}$ for 3 days, and then lyophilized to produce $\mathrm{GC}$ conjugate (GC-BSA) (4.8 mg).

\section{Indirect competitive ELISA for GC}

ELISA for GC was performed as described by Shan et al. ${ }^{8}$ with some modifications. Briefly, 96-well immunoplates were coated with $100 \mu \mathrm{l}$ of GC-BSA conjugate $(10 \mu \mathrm{g} / \mathrm{ml})$ in $50 \mathrm{mM}$ carbonate buffer ( $\mathrm{pH} 9.8$ ) overnight at room temperature. The following day, the plates were washed three times with phosphate buffered saline (PBS) containing $0.05 \%$ Tween 20 (PBST) and treated with $1 \%$ gelatin for $1 \mathrm{~h}$ at room temperature. The plates were washed three times with PBST and reacted with $100 \mu \mathrm{l}$ of equivalent mixtures of GC-MAb 5A8 $(10 \mu \mathrm{g} / \mathrm{ml})$ and serial diluted $\mathrm{GC}$ antigens for $1 \mathrm{~h}$ at room temperature. The plates were washed three times with PBST, and then reacted with $100 \mu \mathrm{l}$ of alkaline phosphatase labelled anti-mouse IgG (1000 fold diluted with PBS) for $1 \mathrm{~h}$ at room temperature. After washing three times with PBST, the substrate solution $(2 \mathrm{mg} / \mathrm{ml}$ $p$-NPP in $50 \mathrm{mM}$ carbonate buffer, $\mathrm{pH} 9.8$, containing $1 \mathrm{mM}$ $\mathrm{MgCl}_{2}$ and $0.1 \mathrm{mM} \mathrm{ZnCl}$ ) was added to each well and incubated for $30 \mathrm{~min}$ at room temperature. The absorbance at $405 \mathrm{~nm}$ was measured using a microplate reader.

\section{Indirect competitive SPR measurement for GC}

For highly sensitive detection, we used an indirect competitive method, which was effective to detect chemical substances with low molecular weight. ${ }^{11-13}$ The refractive index (or incident angle) of $\mathrm{Au}$ thin film modified with an antigen-protein conjugate depends on the concentration of the antigen; this small change can be detected using the SPR. A schematic diagram of the indirect inhibition SPR measurement is shown in Fig. 1. In this method, antigen proteins were immobilized on the sensor chip (Au thin film) by circulating the GC-BSA solution $(1 \mathrm{mg} / \mathrm{ml}$ in PBS) for $1 \mathrm{~h}$ (physical adsorption). The

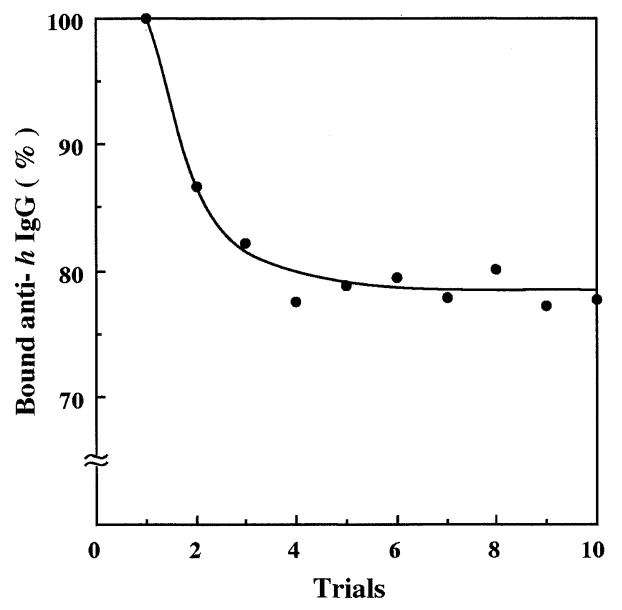

Fig. 2 Effect of the repetitive binding of anti- $h \mathrm{IgG}$ on the immobilized $h \mathrm{IgG}$. Anti- $h \mathrm{IgG}$ injected was $20 \mu \mathrm{g} / \mathrm{ml}$. The flow rate was constantly maintained at $300 \mu \mathrm{l} / \mathrm{min}$.

sensor chip was washed by circulating the carrier buffer (PBS) for $5 \mathrm{~min}$. A BSA solution $(2 \mathrm{mg} / \mathrm{ml}$ in PBS) was circulated for 30 min to reduce any nonspecific adsorption of the antibody. After washing with the carrier buffer (State A in Fig. 1), the GC-MAb $(5 \mu \mathrm{g} / \mathrm{ml})$ solution was allowed to flow for $3 \mathrm{~min}$, and changes in the incident-angle shift $\left(\Delta \theta_{0}\right)$ caused by the association of the antibodies (GC-MAbs) to the immobilized antigens (GC-BSA) was measured (State B). After 3 min, the flowing solution was changed to the carrier buffer and allowed to flow for another $3 \mathrm{~min}$. The sensor chip was then regenerated by the circulation of glycine- $\mathrm{HCl}$ buffer $(10 \mathrm{mM}$, $\mathrm{pH}$ 2.2) for $1.7 \mathrm{~min}$ (State C). After the chip was washed with the carrier buffer and the signal base line was recovered (State D), $1 \mathrm{ml}$ of an equivalent mixture of GC-MAb $(10 \mu \mathrm{g} / \mathrm{ml})$ and an appropriate amount of GC was allowed to flow to obtain a decreased incident-angle shift $\left(\Delta \theta_{1}\right)$ with inhibition by GC (State E). This cycle was performed for mixtures of GC-MAb and serial-diluted GC. A quantitative determination of the antigen concentration can be made from the difference of $\Delta \theta_{0}$ and $\Delta \theta_{1}$. The flow rate was constantly maintained at $300 \mu \mathrm{l} / \mathrm{min}$, and all of the procedures were conducted at room temperature.

\section{Indirect competitive SPR measurement for hIgG}

An $h \mathrm{IgG}$ measurement using SPR sensor was performed by almost the same procedures as for GC, except for the antigen immobilization $(1 \mathrm{mg} / \mathrm{ml} h \mathrm{IgG})$ and anti- $h \mathrm{IgG}$ antibody (final concentration: $20 \mu \mathrm{g} / \mathrm{ml}$ ).

\section{Results and Discussion}

\section{Optimization of the hIgG assay by SPR}

$h \mathrm{IgG}$ was widely used as a model antigen for evaluating the sensor based on the immunoreaction. In order to grasp the properties of the Spreeta ${ }^{\mathrm{TM}}$ sensor kit attached to the flow cell, we first tried to measure $h \mathrm{IgG}$ by an indirect competitive method, and evaluated the sensitivity and accuracy of the assay by using the SPR method. Figure 2 shows the effect of repetitive binding of anti- $h \mathrm{IgG}$ on the immobilized $h \mathrm{IgG}$. As shown in Fig. 2, the amount of associated anti- $h \mathrm{IgG}$ antibody to $h \mathrm{IgG}$ was decreased by about $20 \%$ in the first few trials because of a slight denaturation of the $h \mathrm{IgG}$ protein by the regeneration buffer (glycine- $\mathrm{HCl})$. The response, however, became nearly 


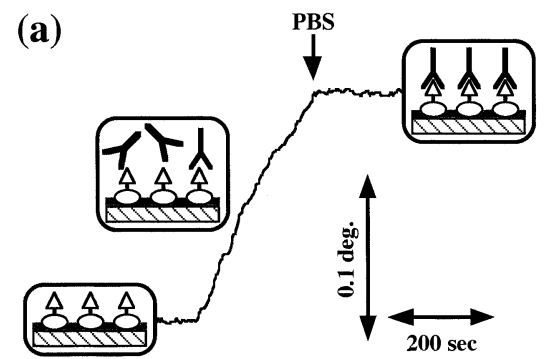

(b)

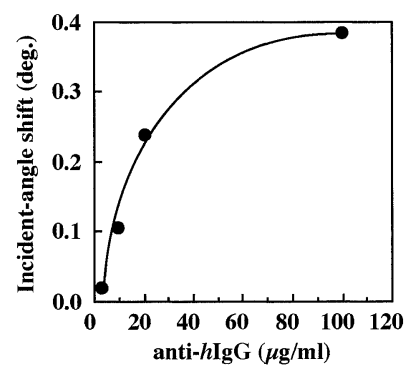

Fig. 3 Response transient of the incident angle of the $h \operatorname{IgG}$ immobilized sensor to the anti- $h \operatorname{IgG}$ (a) and the dependence of the incident angle shift on the anti- $h \mathrm{IgG}$ concentration (b).

constant after five repetitions, indicating that constant results were achieved by this pre-conditioning. The thus-preconditioned $h \mathrm{IgG}$ immobilized chip was exposed to the flow of anti- $h \mathrm{IgG}$ antibody at various concentrations $(2.0-60 \mu \mathrm{g} / \mathrm{ml})$. The response transient of the incident angle of the $h \mathrm{IgG}$ immobilized chip to a flow of $20 \mu \mathrm{g} / \mathrm{ml}$ anti- $h \mathrm{IgG}$ is shown in Fig. 3(a). Upon exposure to the flow of antibodies, the incident angle increased rapidly due to the association of the anti- $h \mathrm{IgG}$ antibody on the sensor chip by antigen-antibody binding, and attained a steady state in about $3 \mathrm{~min}$. The incident-angle shifts, measured by sequential injection of increased antibody concentration, were plotted against the concentration of the antibody. The plots are shown in Fig. 3(b). The incident-angle shift increased rapidly with increasing concentration of the anti$h \mathrm{IgG}$ antibody up to approximately $40 \mu \mathrm{g} / \mathrm{ml}$, and then leveled off. Considering the use of the indirect competitive method, we chose approximately $20 \mu \mathrm{g} / \mathrm{ml}$ anti- $h \mathrm{IgG}$ as the best antibody concentration.

\section{Determination of $h \operatorname{Ig} G$ by $S P R$}

Anti- $h \operatorname{IgG}$ antibody solutions were mixed with $h \mathrm{IgG}$ to prepare mixtures containing the antibody with the final concentration of $20 \mu \mathrm{g} / \mathrm{ml}$ and $h \mathrm{IgG}$ of different concentrations $(0.5-100 \mu \mathrm{g} / \mathrm{ml})$. The mixtures were incubated for $5 \mathrm{~min}$ at room temperature prior to flowing over the $h \mathrm{IgG}$ immobilized chip. The percent inhibition, which was the decrease in the response relative to that of no $h \operatorname{IgG}$ antigen, $\left(\Delta \theta_{0}-\Delta \theta_{\mathrm{i}}\right) / \Delta \theta_{0} \times$ 100 , was plotted against the concentration of $h \mathrm{IgG}$, where $\Delta \theta_{1}$ stands for the incident-angle shift of the i-th mixture of anti- $h \mathrm{IgG}$ and $h \mathrm{IgG}$; the plots are shown in Fig. 4. The percent inhibition was increased rapidly with an increase in the concentration of $h \mathrm{IgG}$ higher than $5 \mu \mathrm{g} / \mathrm{ml}$. The relative standard deviations (RSDs, $n=3$ ) of each point were 1.29, 3.46, 2.65, 3.00, 2.39, and $3.29 \%$ for $0.5,1.0,5.0,10.0,20.0$, and $50.0 \mu \mathrm{g} / \mathrm{ml}$, respectively. These results indicated that high-reproducible measurements can be obtained by using this SPR method. The lowest detection limit is defined as the concentration where the percent inhibition is increased by $15 \%$, which is approximately

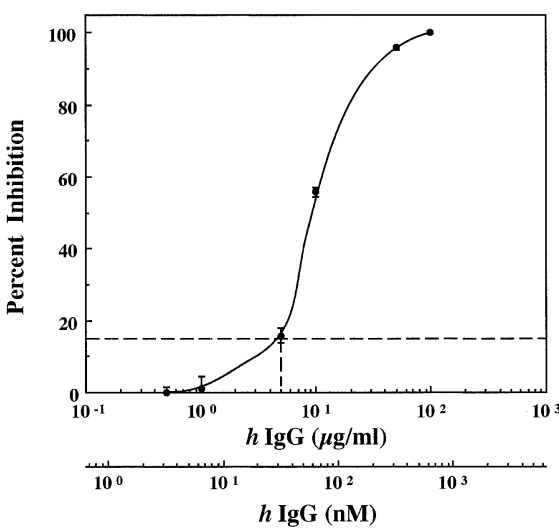

Fig. 4 Determination of $h \mathrm{IgG}$ by the indirect competitive SPR method. The error bars indicate \pm standard deviations $(n=3)$. 20 $\mu \mathrm{g} / \mathrm{ml}$ of anti- $h \mathrm{IgG}$ was used.

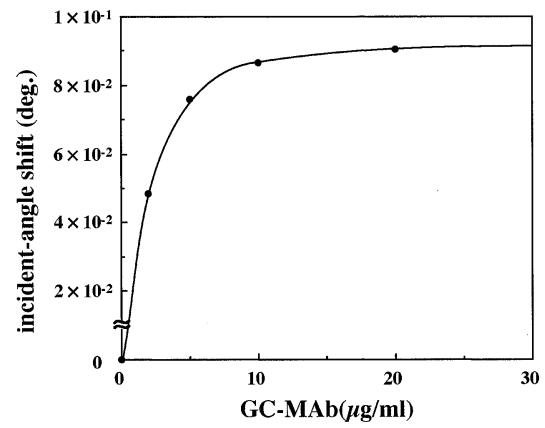

Fig. 5 Dependence of the incident angle shift of the GC-BSA immobilized SPR sensor on the GC-MAb concentration.

three SDs, from the mean incident angle shift observed in the absence of $h \mathrm{IgG}$. The lowest detection limit for $h \mathrm{IgG}$ is approximately $5 \mu \mathrm{g} / \mathrm{ml}$ (corresponding to about $3.3 \times 10^{-8} \mathrm{M}$ ).

\section{Optimization of the GC assay by $S P R$}

A GC-BSA immobilized chip was exposed to the flow of GC$\mathrm{MAb}$ at various concentrations $(2.5-20 \mu \mathrm{g} / \mathrm{ml})$. The incidentangle shifts were plotted against the concentration of GC-MAb; the plots are shown in Fig. 5. The incident-angle shift again increased rapidly with increasing concentration of GC-MAb up to approximately $10 \mu \mathrm{g} / \mathrm{ml}$, and then increased meagerly above this concentration. From this figure, the use of an approximately $5 \mu \mathrm{g} / \mathrm{ml}$ GC-MAb solution is considered to be the best for GC sensing experiments, considering the use of the indirect competitive method.

\section{Detection of GC with SPR and a comparison with ELISA}

GC-MAb solutions $(10 \mu \mathrm{g} / \mathrm{ml})$ were mixed with equal volumes of GC of various concentrations, and incubated for 5 min at room temperature prior to flowing over the GC-BSA immobilized sensor chip. The percent inhibitions were plotted against the concentration of GC in the same way as in the case of $h \mathrm{IgG}$; the plots are shown in Fig. 6. In this case, preconditioning was not required for the association of GC-MAb to the GC-BSA immobilized chip. The RSDs $(n=3)$ of each point were less than $4.0 \%$. The detection of GC was also done by indirect competitive ELISA; the results observed by both the SPR and ELISA methods are compared (Fig. 6). The lowest detection limit for GC by SPR was almost the same as that by 


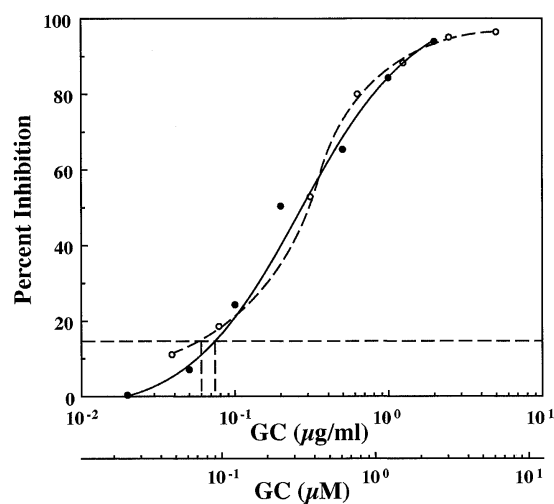

Fig. 6 Standard curve of inhibition by GC. • Indirect competitive SPR method; o, indirect competitive ELISA.

ELISA, $60-75 \mathrm{ng} / \mathrm{ml}$ (corresponding to $7.2-9.1 \times 10^{-8} \mathrm{M}$ ). GC is contained in mg-quantity in plant extracts, ${ }^{7,8}$ whereas, to evaluate the pharmacokinetics and bioavailability of GC, $\mu \mathrm{g} / \mathrm{ml}$ levels of sensitivity should be needed. ${ }^{14,15}$ The SPR method might give a simple and rapid detection of GC for wide applications from plant screening to pharmacokinetic studies.

\section{Evaluation of affinity constants}

To determine an affinity constant $\left(K_{\mathrm{A}}\right)$, or its reciprocal, the dissociation constant $\left(K_{\mathrm{D}}\right)$ is frequently useful in the study of antigen-antibody interactions. The evaluation of $K_{\mathrm{D}}$, however, is an afflictive process because of the different values obtained by the method used for the analysis. The introduction of a convenient method for calculating $K_{\mathrm{D}}$ using indirect competitive ELISAs, based on the method by Friguet et al., ${ }^{16}$ has been followed by its widespread application. Subsequently, a corrected method that takes into account the bivalent nature of IgG was suggested by Stevens. ${ }^{17}$ Seligman $^{18}$ discussed the influence of the solid-phase antigen in indirect competitive ELISAs on the calculated antigen-antibody dissociation constants $\left(K_{\mathrm{D}}\right)$. We first tried to evaluate the values of $K_{\mathrm{D}}$ with our GC determination data obtained in indirect competitive ELISA by using Friguet's, Stevens' and Seligman's methods. The data points for these analyses were used from No. (3) to No. 7 in Fig. 7. Table 1 summarizes the results. The values of $K_{\mathrm{D}}$ ranged from $4.84 \times 10^{-8} \mathrm{M}$ to $19.7 \times 10^{-8} \mathrm{M}$. The highest value was from Friguet's method, which did not incorporate any correction for bivalency. The value $\left(19.7 \times 10^{-8} \mathrm{M}\right)$ from Friguet's method was almost four-fold higher compared with that $\left(4.87 \times 10^{-8} \mathrm{M}\right)$ from Seligman's method, and the value $\left(4.84 \times 10^{-8} \mathrm{M}\right)$ from Stevens' was almost the same as that from Seligman's method. We also estimate the $K_{\mathrm{D}}$ value from the ELISA data reported earlier by Shan et al. ${ }^{8}$ with the same antigen-antibody system by using Seligman's method. The data points for this analysis were used from No. (1)' to No. (5)' in Fig. 7. The evaluated value of $K_{\mathrm{D}}$ was $0.81 \times 10^{-8} \mathrm{M}\left(K_{\mathrm{A}}=1.23\right.$ $\left.\times 10^{8} \mathrm{M}^{-1}\right)$. The value of $0.81 \times 10^{-8} \mathrm{M}$ was approximately onesixth lower than our results $\left(4.87 \times 10^{-8} \mathrm{M}\right)$ and the difference was interpreted by the influence of the amount of solid-phase antigen. The amount of solid-phase antigen used by Shan et al. was $1 \mu \mathrm{g} / \mathrm{ml}$, whereas it was $10 \mu \mathrm{g} / \mathrm{ml}$ by us. Hetherington ${ }^{19}$ investigated the influence of a solid-phase antigen on a competitive ELISA, and found that an eight-fold increase in the amount of solid-phase antigen applied to the microtiter plate caused an approximately five-fold increase in the calculated $K_{\mathrm{D}}$. Seligman ${ }^{18}$ also obtained almost the same tendency of the eight-

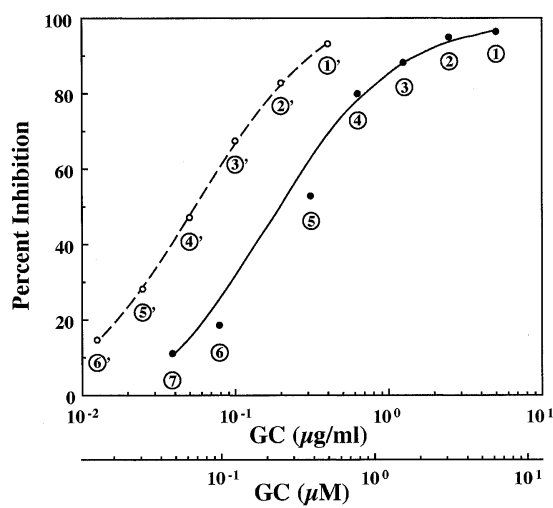

Fig. 7 Plots of percent inhibition versus the GC concentration using indirect competitive ELISA. - our data; $\bigcirc$, data reported by Shan et al. The solid and dashed lines are theoretical inhibition curves from $K_{\mathrm{A}}=2.05 \times 10^{7} \mathrm{M}^{-1}$ and $K_{\mathrm{A}}=1.24 \times 10^{8} \mathrm{M}^{-1}$, respectively.

fold increase in the calculated $K_{\mathrm{D}}$ when the amount of solidphase antigen increased from $6 \mathrm{pmol} / \mathrm{well}$ to $600 \mathrm{pmol} / \mathrm{well}$. The lower amount of solid-phase antigen would lead a more reliable value of $K_{\mathrm{D}}$. The solid and dashed lines in Fig. 7 show theoretical inhibition curves for indirect competitive antigenantibody reactions using our calculated $K_{\mathrm{D}}$-value $\left(4.87 \times 10^{-8}\right.$ $\mathrm{M})$ and that $\left(0.81 \times 10^{-8} \mathrm{M}\right)$ of Shan et al., ${ }^{8}$ respectively, indicating that each measured datum point closely falls on both lines.

Next, we tried to evaluate the affinity constants of the GCMAb to immobilized GC-BSA and GC by using the SPR data. The analyses were followed by a method reported by Sakai et $a l .^{20,21}$ They evaluated the affinity constants relevant to an immunoassay system by assuming a Langmuir-type adsorption model for the immunoreaction. ${ }^{20,21}$ The present system involves two competitive immunoreactions, as follows:

$$
\begin{aligned}
& \mathrm{MAb}+\mathrm{GC}^{-B_{S A}} \text { bound } \stackrel{K_{1}}{\longrightarrow} \text { MAb-GC-BSA } A_{\text {bound }} \\
& \mathrm{MAb}+\mathrm{GC} \stackrel{K_{2}}{\longrightarrow} \mathrm{MAb}-\mathrm{GC}
\end{aligned}
$$

Here, MAb stands for GC-MAb, and $K_{1}$ and $K_{2}$ are affinity constants. Three assumptions are required to correlate the incident-angle shift with each immunoreaction. First, the antigen-antibody reaction will proceed by monovalency. Second, a Langmuir-type adsorption model can be adopted. Third, the incident-angle shift is proportional to the coverage of the adsorption sites (immobilized GC-BSA) by GC-MAb. Based on these assumptions, we can obtain the following equation for the first immunoreaction:

$$
[\mathrm{MAb}] / \Delta \theta_{0}=[\mathrm{MAb}] / \Delta \theta_{0, \max }+1 / \Delta \theta_{0, \max } K_{1}
$$

Here, [MAb] is the molar concentration of antibody, $\Delta \theta_{0}$ is the equilibrium incident-angle shift to a given concentration of antibody, and $\Delta \theta_{0, \max }$ is the maximum incident-angle shift at the full coverage. Assuming the latter immunoreaction also to be in equilibrium, the following equation can be derived:

$$
1 / \Delta \theta=1 / \Delta \theta_{0}+K_{2}[\mathrm{GC}] / \Delta \theta_{0, \max } K_{1}[\mathrm{MAb}]_{0}
$$

Here, $\Delta \theta$ and $\Delta \theta_{0}$ are the angle shifts in the presence and absence of GC, respectively. [MAb] $]_{0}$ is the initial molar concentration of MAb (GC-MAb). 
Table 1 Calculation of dissociation constants by various methods using data from competitive ELISA of GC

\begin{tabular}{cccc}
\hline Method & Formula & $\begin{array}{c}K_{\mathrm{D}} \\
\left(\times 10^{-8} \mathrm{M}\right)\end{array}$ & $\begin{array}{c}K_{\mathrm{A}} \\
\left(=1 / K_{\mathrm{D}}, \times 10^{7} \mathrm{M}^{-1}\right)\end{array}$ \\
\hline $\begin{array}{l}\text { Friguet } \text { et al. } \\
\text { Stevens } \\
\begin{array}{c}\text { correction } \\
\text { Seligman }\end{array}\end{array}$ & $1 / \mathrm{v}=1+K_{\mathrm{D}} / a_{0}$ & 19.7 & 0.51 \\
& $a_{0} / f=K_{\mathrm{D}} /(1-f)+i_{0}$ & 4.84 & 2.07 \\
\hline
\end{tabular}

Analyses were performed using formulae shown above and data points from (3) to (7) of Fig. 7.

$\mathrm{v}=\left(A_{0}-A_{\mathrm{i}}\right) / A_{0}$ where $A_{0}$ is the absorbance without competing antigen and $A_{\mathrm{i}}$ is the absorbance with competing antigen; $a_{0}$, initial concentration of competing antigen; $f=\sqrt{\mathrm{V}} ; i_{0}$, initial antibody concentration.

From Eq. (3), [MAb]/ $\Delta \theta_{0}$ should be linear to [MAb], the slope and the intercept giving values of $\Delta \theta_{0, \max }$ and $K_{1}$, respectively. The data in Fig. 5 are replotted in this way in Fig. 8(a). A linear correlation was obtained, as indicated, which gave $\Delta \theta_{0, \max }=$ 0.099 deg. and $K_{1}=8.69 \times 10^{7} \mathrm{M}^{-1}$. From Eq. (4), the inverse $\Delta \theta$ should be linear to [GC], $K_{2}$ being obtained from the slope and the known values of $\Delta \theta_{0, \max }, K_{1}$ and $[\mathrm{MAb}]_{0}$. The data of SPR in Fig. 6 are replotted in Fig. 8(b). The obtained linear correlation gave $K_{2}=4.64 \times 10^{7} \mathrm{M}^{-1}$. The evaluated $K_{2}$ by SPR is the affinity constant between GC-MAb and free GC, which corresponds to $K_{\mathrm{A}}$ evaluated from ELISA. The value of $K_{2}$ $\left(4.64 \times 10^{7} \mathrm{M}^{-1}\right)$ from SPR is approximately two-fold higher than that $\left(2.05 \times 10^{7} \mathrm{M}^{-1}\right)$ obtained from our ELISA data by using Seligman's method. The reason for this difference is not yet clear, but one of the reasons would be neglecting the bivalent nature of IgG from Eqs. (1) to (4). Seligman's method also has a vulnerable point, because the method does not take into account the interaction between GC-MAb and immobilized GC-BSA, which causes the difference of $K_{\mathrm{A}}$ due to the influence of the amount of solid-phase antigen. One of the advantages of the SPR evaluation method over the ELISA methods is to evaluate each affinity constant between the antibody and the solid-phase antigen $\left(K_{1}\right)$ and between the antibody and the free antigen $\left(K_{2}\right)$. As a whole, we can say that the affinity constant $\left(K_{\mathrm{A}}\right)$ between GC-MAb and GC is on the order of $10^{7} \mathrm{M}^{-1}$.

\section{References}

1. K. Ohtsuki and N. Ishida, Biochem. Biophys. Res. Commun., 1988, 157, 597.

2. R. Doll, I. D. Hill, C. Hutton, and D. L. Underwood, Lancet, 1962, 2, 793.

3. R. Pompei, O. Flore, M. A. Marccialis, A. Pani, and B. Loddo, Nature, 1979, 281, 689.

4. T. Hattori, S. Ikematsu, A. Koito, S. Matsushita, Y. Maeda, M. Hada, M. Fujimaki, and K. Takatsuki, Antiviral Research, 1989, 11, 255.

5. T. G. van Rossum, A. G. Vulto, R. A. de Man, J. J. Brouwer, and S. W. Schalm, Alimentary Pharmacology \& Therapeutics, 1998, 12, 199. (a)

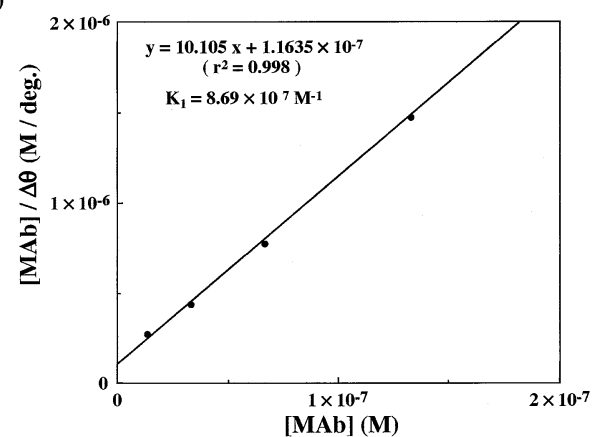

(b)

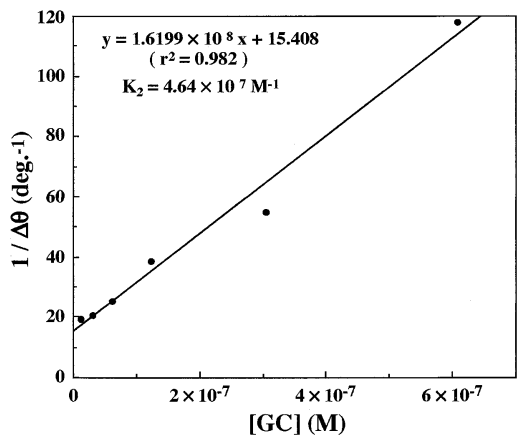

Fig. 8 Graphic analyses for evaluating $K_{1}$ and $K_{2}$. (a) Relationship between $[\mathrm{MAb}]$ and $[\mathrm{MAb}] / \Delta \theta$; (b) relationship between $[\mathrm{GC}]$ and $1 / \Delta \theta$.

6. E. S. Ong and S. M. Len, Anal. Chim. Acta, 2003, 482, 81.

7. H. R. Ren and S. J. Sheu, J. Chromatgr. A, 1993, 653, 184.

8. S. Shan, H. Tanaka, and Y. Shoyama, Anal. Chem., 2001, $73,5784$.

9. F. Deckert and F. Legay, Anal. Biochem., 1999, 274, 81.

10. T. P. Vikinge, A. Askendal, B. Liedberg, T. Lindahl, and P. Tengvall, Biosens. Bioelectron., 1998, 13, 1257.

11. K. V. Gobi, S. J. Kim, R. Harada, and N. Miura, Electrochem., 2003, 71, 430.

12. N. Miura, M. Sakai, G. Sakai, and K. V. Gobi, Chem. Lett., 2002, 31, 342 .

13. N. Miura, M. Sakai, K. V. Gobi, C. Kataoka, and Y. Shoyama, Biosens. Bioelectron., 2003, 18, 953.

14. S. Krahenbuhl, F. Hasler, and R. Krapf, Steroids, 1994, 59 , 121.

15. G. Cantelli-Forti, M. A. Raggi, F. Bugamelli, F. Maffei, A Villari, and N. M. Trieff, Pharmacol. Res., 1997, 35, 463.

16. B. Friguet, A. F. Chaffotee, L. Djavadi-Ohaniance, and M. E. Goldberg, J. Immunol. Methods, 1985, 77, 305.

17. F. Stevens, Mol. Immunol., 1987, 24, 1055.

18. S. J. Seligman, J. Immunol. Methods, 1994, 168, 101.

19. S. Hetherington, J. Immunol. Methods, 1990, 131, 195.

20. G. Sakai, K. Ogata, T. Uda, N. Miura, and N. Yamazoe, Sens. Actuators B, 1998, 49, 5 .

21. G. Sakai, S. Nakata, T. Uda, N. Mira, and N. Yamazoe, Electrochim. Acta, 1999, 44, 3849. 